\title{
Mediação: categoria lógica, ontológica, epistemológica e metodológica
}

\author{
Ana Amélia Lage Martins*
}

Artículo recibido:

10 de octubre de 2018

Artículo aceptado:

27 de febrero de 2019

Artículo de revisión

\section{Resumen}

La categoría mediación se consolidó en el marco teórico de la Ciencia de la Información como un importante operador conceptual. Con significados distintos, su empleo en distintas corrientes teóricas y epistemológicas como modo de pensar las diversas dinámicas que involucran la producción, la organización, el flujo, la comunicación, la apropiación, la circulación, la transferencia, los dispositivos, los registros, los usos, los usuarios y los regímenes de información en diferentes contextos. Se sabe que este constructo polisémico, que ha migrado a diversos campos del conocimiento, está presente en la Filosofía, por lo menos, desde la Antigüedad clásica, habiendo sido desarrollado por

* Universidade Federal do Estado do Rio de Janeiro (UNIRIO), Brasil

$$
\text { anaamelialagemartins@gmail.com }
$$
INVESTIGACIÓN BIBLIOTECOLÓGICA, vol. 33, núm. 80, julio/septiembre, 2019, México,
ISSN: 2448-8321 pp. 133-154 
la dialéctica moderna, que lo tiene como importante categoría de su sistema. El artículo parte de la génesis histórica del concepto de mediación y explora algunos de sus significados dialécticos, demarcando que la mediación es categoría fundamentalmente lógica, ontológica, epistemológica y metodológica.

Palabras clave: Mediación; Mediación Dialéctica; Dialéctica.

Mediation: logical, ontological, epistemological, and methodological category

Ana Amélia Lage Martins

\section{Abstract}

The mediation category was consolidated within the theoretical framework of Information Science as an important conceptual operator. With different meanings, mediation has been used by different theoretical and epistemological currents, as a way of thinking the diverse dynamics that involve the production, organization, flow, communication, appropriation, circulation, transfer, devices, registers, uses, users and regimes of information in different contexts. It is known that this polysemic construct, which migrated to different fields of knowledge, has been present in Philosophy since at least Classical Antiquity, and has also been developed by modern dialectics, which considers it as an important category of its system. Considering the historical genesis of the concept of mediation, this work explores some of its dialectical meanings, pointing out that mediation is fundamentally an ontological, epistemological, logical and methodological category. Conclusively, it points out questions that the dialectical perspective of mediations introduces in the construction and understanding of the informational object.

Key Words: Mediation; Dialectical Mediation, Dialectics. 


\section{INTRODUÇÃO}

$\mathrm{O}$ s significados que ganhou a mediação no campo da Ciência da Informação têm sido, desde os últimos anos, objeto recorrente de discussões teóricas, investigação e sistematizações. O ponto de partida deste esforço que vem produzindo considerável e importante acúmulo no campo é a identificação, assim como faz Araújo (2016), dos termos mediação/mediações/mediadores como importantes categorias do recente quadro conceitual da área.

$\mathrm{Na}$ análise do "objeto informacional" a mediação é empregada, conforme evidencia a literatura (Martins, 2010; Farias e Farias, 2017; Jeanneret, 2005; Silva, 2010; Perroti e Pieruccini, 2014; Davallon, 2007; Regimbeau, 2011; Silva et al., 2018), especialmente para destacar:

a) A existência de elos intermediários ou de um "terceiro elemento" na produção, organização, circulação e apropriação da informação.

b) A ação realizada por um agente, muitas vezes o (a) bibliotecário (a) ou outros profissionais que intervém de alguma maneira no ciclo informacional e promove a aproximação e a interpretação de bens simbólicos.

c) O fato de os significados e os sentidos atinentes ao todo procedimento informacional não se darem de forma imediata, mas apenas por processos onde atuam diversas intervenientes: materiais, técnicas, simbólicas, cognitivas, etc.

d) O caráter fundamentalmente mediado/mediatizado da produção da realidade a partir da penetração intensa das tecnologias da informação e comunicação nas diferentes esferas da vida individual e coletiva.

e) A dinâmica complexa da produção de hegemonias e, sobretudo, contra-hegemonias a partir da cultura, da comunicação e informação.

Considerando a pluralidade das acepções que têm o termo no campo dos estudos informacionais e comunicacionais e da inexistência de consenso sobre seus significados, não é intenção deste trabalho apresentar os diversos sentidos que o termo mediação ganhara dentro da Ciência da Informação, o que se configuraria em um trabalho à parte.

Cumpre destacar, no entanto, que além do seu uso em noções operativas e de vasto significado como "mediação da informação" seu emprego, feito amiúde no plural "mediações", pode designar ora o conjunto de valores, práticas compartilhadas, lugares de cultura e memória que transcende o cotidiano das trocas (Jeanneret, 2005), ora a instância que garante, na comunicação 
e na vida social, a articulação entre as dimensões individual do sujeito e sua singularidade e a dimensão coletiva de sociabilidade e vínculo social (Lamizet, 1998), promovendo uma passagem ou o elo social (Dufrêne e Gellereau, 2004).

Mediar também compreende, frequentemente, a ação de um elemento terceiro no processo de construção de sentidos, do qual decorrem transformações nos envolvidos em interação (Davallon, 2007) e também pode assinalar as articulações que, a partir dos dispositivos, estruturam lugares, textos, espaços e acervos, influenciando as interpretações e produzindo objetos mistos e portadores de sentidos (Marteleto e Andalécio, 2005). Por esta perspectiva, se constitui em atividade produtiva e criativa que intervém no curso da comunicação e lhe confere uma dimensão nova (Jeanneret, 2005).

A incorporação da categoria mediação no âmbito do aparato teórico-conceitual empregado pela Ciência da Informação está ligada, historicamente, às diversas transformações sociais ocorridas a partir da década de 1970 nas sociedades ocidentais que tiveram como contexto geral uma reorganização do sistema capitalista e suas consequentes implicações na vida social, cultural e política.

Este cenário foi pano de fundo de reorientações teóricas paradigmáticas no campo das Ciências Sociais, a partir do qual a noção de mediação/ mediações começa a fertilizar e a ser utilizada de modo mais sistemático, o que pôde ser visto na perspectiva crítica e multidisciplinar dos Estudos Culturais, na teoria da mediação social de Martin-Serrano e nos estudos de recepção da América Latina.

$\mathrm{Na}$ Ciência da Informação brasileira a mediação começa a circular a partir da década de 1980, tanto para a defesa do caráter público e democrático das bibliotecas quanto para compreensão das novas relações informacionais entre Estado e sociedade civil. A Biblioteconomia e a Ciência da Informação marcam-se, neste momento, por uma preocupação crescente em apreender o "fenômeno" ou "objeto informacional" a partir dos contextos históricos, sociais, econômicos, políticos e culturais e, ao mesmo tempo, em dar respostas operacionais ao "imperativo tecnológico" que adivinha segundo discursos que reverberavam as necessidades do capital e ganhavam força no campo à época com as novas mídias e tecnologias de comunicação (Freitas, 2001), responsáveis por instaurar "novas mediações" na produção, organização e acesso aos registros informacionais.

A consolidação definitiva e integração da categoria à terminologia do campo, na América Latina, resultou também da ampla recepção que teve a "teoria das mediações" de Martín-Barbero, que em 1987 propôs deslocar o foco do pensamento sobre as relações operadas entre comunicação, ideologia e hegemonia (que orientava o pensamento sobre as indústrias culturais) "dos meios às mediações”. A categoria, que também não goza de sentido na teoria 
do autor, foi utilizada, de maneira geral, como modo de evidenciar "as articulações entre as práticas de comunicação e movimentos sociais, as diferentes temporalidades e a pluralidade de matrizes culturais" (Martín-Barbero e Barcelos, 2000: 161) e demarcar que entre a emissão e a recepção ou "entre estímulo e resposta há um espesso espaço de crenças, costumes, sonhos, medos, ritualidades, memórias, tudo o que configura a cultura cotidiana" (Martín-Barbero, 1997: 262).

Pode-se afirmar que a partir de Martín-Barbero, a mediação se converte definitivamente, no campo da informação, em uma categoria intrinsecamente vinculada aos processos de significação e ressignificação da informação, de produção social dos sentidos e à compreensão epistemológica da informação e da comunicação a partir da cultura.

A influência de Martín-Barbero contribuiu, portanto, para sedimentar uma compreensão da mediação como relacionada ao "ato constitutivo dos processos de construção de sentidos e instância produtora de significação" (Perroti e Pieruccini, 2014: 19).

Se, por um lado, a integração definitiva do termo mediação aos estudos sobre cultura, comunicação e informação é relativamente recente, por outro, seu emprego pela Filosofia é feito há centenas de séculos.

Antes de o polissêmico termo migrar para o campo da Comunicação e da Informação, onde ganhou e ainda ganha diversos sentidos, ele se apresentava como um elemento da lógica e epistemologia na Filosofia Ocidental desde, pelo menos, a Antiguidade Clássica, quando fora utilizado através da perspectiva do "meio-termo" ou "termo médio" nas Teorias do Conhecimento, na ética aristotélica e no silogismo (Abbagnano, 2007).

Diversas obras de referência fontes do conhecimento historicamente legitimado de um campo (na acepção que faz Pierre Bourdieu) da Filosofia e Ciência Sociais evidenciam que o desenvolvimento da mediação como categoria tem como marcos históricos fundamentais o sistema dialético construído por Hegel, onde figura como "categoria central" (Bottomore, 1988) e, mais tarde, a dialética materialista histórica de Marx.

Tendo em vista a potencialidade para a construção de conhecimentos que traz a reflexão sobre a gênese histórica e filosófica dos conceitos, este trabalho objetiva elucidar a gênese filosófica da mediação, cujo marco de desenvolvimento é a dialética, demarcando que a categoria tem caráter fundamentalmente ontológico, lógico, epistemológico e metodológico.

De modo conclusivo tece considerações sobre como a compreensão dialética da categoria pode contribuir para a construção do objeto informacional e para a fundamentação teórica e epistemológica da categoria no campo de estudos da informação. 
Uma breve pesquisa por obras de referência evidencia que a palavra mediação, na Filosofia Ocidental, tem como marcos principais: o pensamento teológico e a "antiga lógica" da Antiguidade Clássica; o termo-médio do silogismo e a dialética moderna (Abbagnano, 2007; Lalande, 1993; Legrand, 1991; Japiassú e Marcondes, 2001; Williams, 1985).

O primeiro está ligado à noção de intermediação (até hoje imediatamente "colada" ao termo mediação), a partir da qual o pensamento teológico da Antiguidade atribuía aos anjos, demônios e sarcedotes uma "função mediadora entre os deuses e os homens" (Abbagnano, 2007: 655), ideia que também pode ser vista, mais tarde, na doutrina cristã que supõe ser Cristo um mediador entre a humanidade e Deus.

Japiassú e Marcondes (2001: 127) localizam o significado original da mediação, em um sentido genérico, na "ação de relacionar duas ou mais coisas, de servir de intermediário ou 'ponte' e de permitir a passagem de uma coisa à outra", estando ligada, na tradição filosófica clássica, "ao problema da necessidade de explicar a relação entre duas coisas, sobretudo entre duas naturezas distintas, como o mundo sensível e o mundo inteligível, em Platão; Deus e o homem, na escolástica (Japiassú e Marcondes, 2001: 127).

Concebida também pelo pensamento filosófico clássico como "função que relaciona dois termos ou dois objetos em geral" (Abbagnano, 2007: 655), a mediação pode ser identificada especialmente nas provas da demonstração, na reflexão e no termo-médio do silogismo.

De acordo com Lalande (1993: 656), na linguagem da "antiga lógica", um termo mediato compreendia um termo-médio e uma conclusão mediata a "correctamente extraída de uma maior por intermédio de uma menor".

O termo-médio, cujo "papel de mediador no raciocínio permitia que se tornasse possível uma conclusão a partir de determinada premissa" (Ferrater Mora, 1982: 1918) foi entendido seminalmente como aquilo que torna possível o raciocínio já que "em um processo discursivo, tanto dedutivo como indutivo, são necessários termos ou juízos que 'medeiam' entre o ponto de partida e a conclusão (Pugliesi e Bini, 1997: 252).

O fundamental "termo-médio" cumpre, no silogismo, com a função de promover a conexão entre as premissas, permitindo que o raciocínio dedutivo se estruture. Para Aristóteles, o silogismo possui como características: ser mediado (porque não pode ser apreendido imediatamente a partir da percepção, mas pelo raciocínio), dedutivo (porque parte da verdade de premissas universais para se chegar a outras premissas) e necessário (porque estabelece uma 
cadeia causal entre as premissas). Abbagnano (2007: 655) lembra que "segundo Aristóteles, o silogismo é determinado pela função mediadora do termo médio, que contém um termo e é contido pelo outro termo".

Além do silogismo, sobre o qual debruçou-se Aristóteles especialmente em seu Organon, o meio-termo é bastante relevante em Ética a Nicômaco, quando o filósofo apresenta a virtude como uma espécie de média, uma mediedade (mesotês) entre o excesso e a falta: "o que dista igualmente de cada um dos extremos, que justamente é um único e mesmo para todas; por meio relativo a nós, o que não excede nem falta" (Aristóteles, 2001: 17).

Para o filósofo, a virtude moral deve ter "o atributo de visar o meio-termo", pois é ela que

diz respeito às paixões e ações em que o excesso é uma forma de erro, assim como a carência, ao passo que o meio-termo é uma forma de acerto digna de louvor; e acertar e ser louvada são características da virtude. Em conclusão, a virtude é uma espécie de mediania, já que, como vimos, ela põe a sua mira no meio-termo (Aristóteles, 2001:29).

Abbagnano (2007) lembra também que a noção de mediação como indispensável em qualquer processo de raciocínio, também foi indicada na Lógica de Port-Royal e por D'Alembert. A primeira consigna que "quando apenas a consideração de duas ideias não é suficiente para se julgar se o que se deve fazer é afirmar ou negar uma ideia com a outra, é preciso recorrer a uma terceira ideia, simples ou complexa e esta terceira ideia chama-se intermediária" (Abbagnano, 2007: 655). D’Alembert colocava a mediação no confronto entre objetos distantes, de modo que para ele

toda a lógica se reduz a uma regra muito simples: para confrontar dois ou mais objetos distantes uns dos outros utilizamos objetos intermediários. O mesmo acontece quando queremos confrontar duas ou mais ideias; a arte do raciocínio nada mais é que o desenvolvimento desse princípio e as consequências dele resultantes (Abbagnano, 2007: 655).

Aproximando-se historicamente do termo mediação, Grisales Franco e Gonzalez Agudelo (2010) apontam que desde o seu emprego na Antiguidade é possível perceber a mediação como um modo de relacionar elementos tidos como contrários. Para os autores, ela se instaura "na terceira espécie de essência intermediária que, por sua vez, porta algo de um e do outro e que também se localiza a igual distância de um e de outro para compor um 'todo' com as essências contrárias" (Grisales Franco e Gonzalez Agudelo, 2010: 119. Tradução minha). O estabelecimento da ideia de mediação visando um 
modo de relacionar contrários, indicaria, assim, sua lógica eminentemente dialética.

No século XIX, a mediação se converterá uma categoria central da dialética (Bottomore, 2010), atingindo a plenitude de seu desenvolvimento em Hegel (Almeida, 2002), considerado o "filósofo da mediação" (Cabrera, 2013) ou "o divisor de águas na progressão conceitual da mediação” (Consani, 2008: 83).

\section{O Lugar dA MEdiação NA DIALÉTICA}

\section{O sistema dialético de Hegel}

Embora tenha sua gênese localizada em diferentes momentos históricos do pensamento filosófico, como em Zênon de Eleia (aprox. 490-430 a.C.), Heráclito de Éfeso (aprox. 535 a.C.-475 a.C), Sócrates (aprox. 469 a.C.-a.C. 399), Platão (428/427-348/347 a.C), dentre outros, a dialética, como sistema lógico filosófico, ou como ciência, é organizada e sistematizada a partir do trabalho de Hegel, no século XIX.

Partindo de um diálogo crítico com idealismo subjetivista de Fitche e sua crítica a Schelling, do questionamento de Jacobi acerca da possibilidade do conhecimento imediato de Deus, das observações de Vico sobre a fragmentação da realidade unitária empreendida pelo entendimento cartesiano, do logos de Heráclito, da crítica ao dualismo entre sujeito e objeto de Kant e à identidade em Aristóteles, dentre diversas outras referências da tradição filosófica, Hegel formula sua lógica dialética como um sistema das leis do movimento da realidade e, ao mesmo tempo, do pensamento que reflete a realidade.

A base de seu sistema se assenta, em primeiro momento, na problemática da contradição entre a unidade essencial do processo real e a unilateralidade da faculdade humana do entendimento, orientada para o fenômeno parcial (Kofler, 2010).

Para a proposição de sua moderna concepção da dialética, o filósofo alemão considera que a lógica não se esgota na lógica formal sendo esta, apenas, um momento subordinado daquela, e que a contradição se apresenta como categoria explicativa fundamental para a apreensão da essencialidade do ser, que coincide com a essencialidade do pensamento. 
O sistema científico desenvolvido por ele especialmente nas obras $\mathrm{Fe}$ nomenologia do Espírito (1807), Ciência da Lógica (1812) e Enciclopédia de Ciências Filosóficas (1817) postula que o conhecimento da verdade exige a apreensão do próprio movimento da substância, que constitui processualmente com a consciência uma unidade dialética.

Assim, a superação da questão kantina acerca da impossibilidade de conhecimento da "coisa-em-si" é empreendida por Hegel através da afirmação da identidade existente entre o sujeito do conhecimento e a realidade e das categorias de pensamento como estruturas mesmas da realidade.

$\mathrm{Na}$ estruturação do seu sistema lógico, ele incorpora a contradição como categoria do pensamento (o que não era contemplado pela lógica formal), propondo que a análise de um conceito devesse ter como princípio a sua negação, ou seja, a consideração daquilo que ele não é. Tomando o conceito de "ser", postula que é preciso contrapor-lhe o "não ser", que também passa a constitui-lo e a desenvolver o conceito "vir a ser", o qual implica no desaparecimento e reaparecimento tanto do ser como do nada um no outro. A contradição se apresenta, dessa maneira, como um princípio básico a partir do qual os seres e a realidade, a partir do movimento, existem.

Hegel concebe que toda a realidade (natural, social, subjetiva), se constitui pela prática objetivante do "Espírito" (Geist), o sujeito histórico-mundial. O Geist engendra a realidade objetiva por meio de um processo de exteriorização ou auto-objetivação e, no processo, se constitui reflexivamente.

Considerando o princípio da totalidade, uma das questões centrais no desenvolvimento da lógica hegeliana diz respeito a questão do começo da Filosofia, ou seja, de onde o pensamento dialético deve partir: do singular, do objeto em sua manifestação fenomênica, ou do todo?

Em Ciência da Lógica, Hegel desenvolve seu pensamento sobre a questão do começo da ciência, partindo da seguinte questão: "o início da filosofia deve ser algo mediado ou algo imediato?” (Hegel, 2011: 49).

Para buscar responder a esta questão, ele demarca duas tendências do pensamento: a partir do conteúdo, "o princípio é um conteúdo de algum modo determinado: a água, o um, a ideia, a substância, a mônada, etc" (Hegel, 2011: 49) e a partir da "filosofia do eu".

A necessidade de começar com o eu, explica Hegel, resulta de uma representação não mediada de que é preciso encontrar uma "primeira verdade" da qual se possa deduzir todas as outras- e esta primeira verdade deveria ser uma "certeza imediata".

O "eu" compreenderia esta primeira verdade na medida em que carrega consigo a "a certeza simples de si mesmo" (Hegel, 2011: 52), ao contrário do conteúdo que não está estabelecido de imediato por sua essência. Este "eu" 
seria, contudo, um ponto de vista arbitrário, não se distinguido da afirmação de outro ponto de vista, o empírico, considerando que ele apenas representaria um dos estados empíricos da consciência, tanto quanto qualquer outro estado, e que a vivência do eu pode variar de natureza conforme os sujeitos. Ele igualmente precisa estar submetido a determinações prévias mais concretas, não sendo, portanto, mais certo do que qualquer outro objeto do pensamento.

Considerando que nem o sujeito nem o objeto podem compreender o começo da filosofia, a identidade de ambos, o todo que se obtém mediante a equalização da realidade com o Espírito Absoluto, que "se reconhece a si mesmo no nível mais elevado do seu desenvolvimento” (Hegel, 2011: 63) poderia ser o começo. Contudo, ele ainda não está dado já em si mesmo ao pensamento, sendo conceitualizavel mediante o acompanhamento do processo de sua emergência, do desenvolvimento dos seus momentos na forma de sua afirmação, negação e superação no interior do processo.

O conhecimento do absoluto que constitui a verdade mais concreta, a verdade última de todo o ser, assim, somente se completa mediante seu desenvolvimento temporal em um processo totalizador, de modo que a essência ou a verdade não podem ser acessadas de modo imediato ao fenômeno, no objeto singular, mas somente tendo em vista suas mediações.

O começo se daria, assim, de forma circular, a partir do resultado, do ser, na relação entre o imediato e o mediato, entre o singular e o todo, já que "[...] o essencial não é tanto que o começo seja um imediato puro, senão que o seu conjunto seja uma recorrência circular em si mesmo, em que o Primeiro se volte também o Último, e o Último se volte também o Primeiro" (Hegel, 2011: 59).

$\mathrm{O}$ avanço do caminho estabelecido como começo, será alcançado, então, pelo "método da mediação dialética", que corresponde à essência do próprio ser (Kofler, 2010). A mediação (vermittlug) será, portanto, colocada como um operador fundamental no sistema lógico hegeliano, essencialmente relacionado à possibilidade do conhecimento e da determinação do Ser. Será, neste sentido, categoria que expõe a articulação das manifestações no âmbito da totalidade, ou seja, os nexos dos fenômenos no interior do processo histórico.

Assim, pela perspectiva dialética hegeliana, os fenômenos não podem ser considerados de maneira isolada, mas somente na sua conexão dialética, o que implica a necessidade de relação entre as partes de uma totalidade complexa.

Conforme sinaliza Kofler (2010: 49): “o modo pelo qual o meramente sabido se torna reconhecido consiste na superação do seu ser isolado e em sua restituição ao nexo da totalidade a que pertence - a chamada mediação" (grifo meu).

O movimento e o conhecimento do real pela dialética hegeliana implicam, portanto, a passagem de três momentos: do imediato ou do universal 
abstrato, da sua negação e o da totalidade, do resultado que conserva e contém nele o momento da negação e da mediação e que é parte do processo totalizador. Mediação significa tanto que os momentos são dialeticamente mediados no interior do processo real quanto que a pesquisa teórica desta mediação real se faz através do método da mediação.

Sistematizar a compreensão de Hegel sobre a mediação e o papel específico desta categoria na construção do seu sistema lógico, que não é único, é um trabalho de extrema complexidade que reflete a complexidade do pensamento do filósofo e a amplitude dos temas abarcados por ele.

São poucos os trabalhos em língua portuguesa e inglesa que tentaram identificar sua função no âmbito da filosofia hegeliana. O'Connor (1999) identificou, em Ciência da Lógica, quatro versões diferentes para a mediação as quais nomeou:

1) Tese de elevação: compreende uma perspectiva em que a mediação é o mecanismo intelectual pelo qual passa-se da contingência à necessidade.

2) Tese transcendental: os processos de conhecimento não podem ser explicados de forma coerente sem referência a um elemento não-imediato (e esse elemento é mediação).

3) Tese de conteúdo: a possibilidade de conteúdo é determinada pela forma.

4) Tese genética: uma pré-condição necessária de qualquer fato é que sua produção histórica é, nesse sentido, mediada, ou seja, a gênese de uma coisa ou um estado de coisas é sua mediação.

Pode-se dizer, de maneira geral, que a mediação na fundamentação de seu sistema lógico:

a) Implica relações, nexos e articulações a partir do movimento da negação e reflexão.

b) Não se configura como simples intermediação entre os termos, mas também como relação interna do termo consigo mesmo.

c) Existe na intricada relação entre as partes da totalidade complexa.

d) Se dá na relação com o imediato.

e) Localiza-se na interconexão do universal e do singular a partir do particular.

f) Está implicada com as determinações do ser.

g) Totaliza aspectos em um todo internamente relacionado 
h) Estabelece uma nova relação interna do termo;

i) Compreende o modo de existência do ser relacionado.

j) Funda o devir, o caráter processual do ser.

k) Existe real e racionalmente.

1) Permite a passagem da aparência para a essência e desta para aquela.

m) Ressalta a unidade interligada de determinações mesmo opostas que colocam o problema da igualdade.

n) Existe na natureza e na história.

o) Está ligada às determinações efetivas da História (Hegel, 1992; 2011; O’Connor, 1999; Inwood, 1997; Rambaldi, 1989).

De acordo com Kofler (2010: 48), é precisamente, no conceito de mediação que Hegel revela claramente que sua teoria do conhecimento pretende ser (e para Kofler ela é) ao mesmo tempo uma ciência do ser e do método. "Fora da mediação, algo pode ser familiar, mas não reconhecido".

Para Guarady (1983: 28), afirmar que o método do conhecimento é dialético é "dizer que não poderia existir conhecimento imediato. É negar somente a possibilidade de possuir a verdade por uma intuição sensível, direta, mas também de alcançar a verdade por um conceito isolado".

Leitor e crítico da obra de Hegel e defensor da dialética como método revolucionário, Karl Marx continuou, de certo modo, a desenvolver o sistema dialético hegeliano, observando, contudo, que ele estava "invertido", já que, para ele, não é a consciência que determina o ser, mas o ser que determina a consciência. A dialética necessitava, assim, que a ordem dos termos fosse alterada e seu caráter idealista superado.

\section{Mediação no materialismo histórico de Marx}

A dialética materialista histórica construída por Marx no final do século XIX busca apreender e explicar a realidade a partir do processo histórico de produção da vida material tendo como propósito compreender "como os indivíduos produzem a sociedade e a produção de indivíduos socialmente determinados" (Marx, 2008: 237).

A diferença elementar entre o sistema de Hegel e Marx se assenta na consideração, para o segundo, de que a produção da vida material seria determinante da produção tanto do ser quanto do pensamento, já que ela é a condicionante fundamental do conjunto da vida social, política e espiritual em todos os momentos históricos. 
Embora sinalizando uma diferença fundamental entre a sua dialética e a de Hegel, Marx emprega em seu método o núcleo racional do sistema hegeliano tendo como eixo a contradição, a transitoriedade, a negatividade, o devir, o universal, o particular, a reconstrução histórica e, também, o conceito que aqui nos interessa mais especificamente: a mediação.

Considerando o profundo sentido histórico do sistema dialético hegeliano, Marx concebe a existência de um movimento totalizador da realidade social que se organiza no tempo a partir do plano material, do conjunto de esforços que os seres humanos, em relações entre si, fazem na apropriação e transformação da natureza para a satisfação de suas necessidades. A perspectiva materialista-histórica é, portanto, o pilar da dialética marxiana e do seu método, a qual pode ser compreendida, em termos gerais, como uma reconstrução da dialética hegeliana "despojada da sua forma idealista" (Enge1s, 2008: 282).

Embora a questão teórica e metodológica das mediações não tenha sido formalmente tratada por Marx, como lembra Ciavatta (2001), ela se apresenta no contexto metodológico geral a partir do qual ele construiu sua obra.

Assim como para Hegel, a mediação, além de ser operador lógico, tem sentido ontológico, na medida em que ele concebe o trabalho como mediador entre humanos e a natureza e identifica na atividade produtiva do "ser natural automediado" a condição vital da autoconstituição humana, o que torna possível a existência do ser social (Bottomore, 2010). Para ele:

como criador de valores de uso, como trabalho útil, o trabalho é, assim, uma condição de existência do homem, independente de todas as formas sociais, eterna necessidade natural de mediação do metabolismo entre homem e natureza e, portanto, da vida humana (Marx, 2011: 167).

Ela é também uma categoria fundamentalmente epistemológica relacionada à possibilidade de conhecimento como produto da mesma mediação ontológica derivada da relação entre humanos e natureza e da humanidade entre si e do necessário movimento, na construção do conhecimento, da passagem do real empírico ao real concreto pela mediação do abstrato.

O método empregado por Marx parte da concepção que a investigação "tem de apoderar-se da matéria, em seus pormenores, de analisar suas diferentes formas de desenvolvimento, de perquirir a conexão íntima que há entre elas" (Marx, 2002: 28). Para isso, metodologicamente, a mediação, assim como foi para Hegel, será uma categoria de grande relevância no caminho racional que desvela a "conexão íntima" que compreende o concreto, ou seja, "a síntese de muitas determinações, a unidade do diverso" (Marx, 2008: 258). 
Ela indica, assim, os elos reais entre fenômenos, a concatenação e interação de todos os aspectos e momentos do objeto dado imediatamente no real.

Ao criticar o método perseguido pela Economia desde o século XVII que começa sempre do "todo vivo", do real imediato dado de forma simples, Marx inicia sua análise a partir da forma mais elementar da economia burguesa, a mercadoria, como modo de perseguir o caminho que leva do "concreto real ao concreto pensado".

Ele considera que a mercadoria tem sua existência vinculada a uma totalidade que em sua concreticidade se distingue profundamente do real imediato, ou empírico, do qual partiam os economistas clássicos.

Buscando, assim, pelas "múltiplas determinações" da mercadoria, primeiro a partir da produção geral, ele afirma que é preciso considerar que toda produção é apropriação da natureza pelo indivíduo no interior de e mediada por uma determinada forma de sociedade e que:

a produção é imediatamente consumo e o consumo é imediatamente produção. Cada um é imediatamente seu contrário. Mas tem lugar, simultaneamente, um movimento mediador entre ambos. A produção medeia o consumo, cujo material cria, consumo sem o qual faltaria-lhe o objeto. Mas o consumo também medeia a produção ao criar para os produtos o sujeito para o qual são produtos. Somente no consumo o produto recebe o seu último acabamento (Marx, 2011: 64. Grifo meu).

O "filósofo da práxis" ressalta que a produção não é apenas meio para o consumo e o consumo, finalidade para a produção, na medida em que cada qual fornece ao outro o seu objeto: a produção o objeto externo do consumo, o consumo o objeto representado da produção. Na verdade, "cada um deles não apenas é imediatamente o outro, nem tampouco apenas o medeia, mas cada qual cria o outro à medida que se realiza" (Marx, 2011: 75, grifo meu).

A produção também imprime ao consumo, a partir da mediação, um modo específico de consumo.

O objeto não é um objeto geral, mas um objeto determinado, que foi consumido de uma certa maneira por mediação, mais uma vez da própria produção. A fome é fome, mas a fome que se satisfaz com carne cozida, que se come por meio de uma faca ou de um garfo, é uma fome muito distinta da que devora carne crua com ajuda das mãos, unhas e dentes. A produção não produz, pois, unicamente o objeto do consumo, mas também o modo de consumo, ou seja, produz objetiva e subjetivamente. A produção cria, pois, consumidores (Marx, 2008: 268. Grifo meu).

A criação de consumidores a partir de um modo de consumo é fruto, portanto, de uma mediação da produção. A produção produz o consumo na medida em que cria o modo determinado, que é também mediação do consumo. 
A produção, assim, não somente provê de materiais a necessidade como também provê de necessidades os materiais, ou seja, a produção não somente "produz um objeto para o sujeito, mas também um sujeito para o objeto" (Marx, 2008: 248).

A mercadoria, por seu turno, determinada como valor de troca:

é equivalente, em proporção determinada (proporcionalmente ao tempo de trabalho nela contido), a todos os outros valores (mercadorias); mas a mercadoria não corresponde imediatamente a essa sua determinabilidade. Como valor de troca, é diferente de si mesma em sua existência natural. É preciso uma mediação para pô-la enquanto tal (Marx, 2011: 200. Grifo meu).

A mediação está implicada, portanto, na criação de uma forma de valor, o valor de troca da mercadoria, que pela mediação vai se diferenciar de sua determinibilidade essencial, o seu valor de uso.

Marx aponta que a forma-mercadoria está encoberta por um caráter misterioso que consiste em sua aparência, à primeira vista, de uma "coisa óbvia, trivial" (Marx, 2012: 110).

Este caráter misterioso não resulta do valor de uso da mercadoria, mas decorre de sua própria transformação, pela mediação, na forma mercadoria, processo no qual:

a igualdade dos trabalhos humanos assume a forma material da igual objetividade de valor dos produtos do trabalho; a medida do dispêndio de força humana de trabalho por meio e sua duração assume a forma da grandeza de valor dos produtos do trabalho; [...] as relações entre os produtores, nas quais são realizadas aquelas determinações sociais de seus trabalhos, assumem a forma de uma relação social entre os produtos do trabalho (Marx, 2015: 111).

Assim, o modo objetivo com que se apresentam a mercadoria e sua circulação nas sociedades burguesas produz um ocultamento das reais condições de produção dos objetos ou, das relações sociais de produção, de modo que "a forma-mercadoria e a relação de valor dos produtos em que ela se expressa não tem absolutamente nada a ver com sua natureza física e as relações reais que dela resultam" (Marx, 2015: 111).

A mediação está ligada, assim, a dimensão fetichista do mundo das mercadorias que surge do peculiar caráter social do trabalho nas sociedades capitalistas que produz a forma-mercadoria.

Problematizando a circulação, que se evidencia na superfície da sociedade burguesa como "imediatamente dada", ele também apontará que esta existe 
somente à medida que é incessantemente mediada. Considerada em si mesma, a circulação é a mediação de extremos pressupostos. Mas não põe esses extremos. Por conseguinte, ela própria tem de ser mediada não só em cada um de seus momentos, mas como totalidade da mediação, como processo total. É por isso que seu ser imediato é pura aparência (Marx, 2011:312. Grifo meu).

Por isso ele afirma, nesta mesma passagem, que "a circulação é o fenômeno de um processo transcorrendo por trás dela” (Marx, 2011: 312), é um fenômeno de mediação que se processa, ao cabo, como um movimento de aparências.

O conceito de forma (forma-mercadoria, a forma-valor, a forma-dinheiro, a forma-salário etc), compreende o centro do significado da mediação em Marx, conceito que, para Gunn (1987) tem por finalidade, ao cabo, revelar as aparências das relações de classe. Por esta perspectiva (que somente pode ser pensada por meio de seu elo dialético com o conteúdo) a mediação apontaria, assim, para o modo de existência ou a aparência dos fenômenos cuja essência, pelas mediações, se dá a ocultar, mas também a "aparecer", no sentido hegeliano que indica a ação da palavra.

Assim, o valor de troca compreenderia a mediação, ou seja, o modo de existência ou aparência de valor de uso, por sua vez, mediado pela forma-dinheiro (forma de existência do valor de uso), a mais-valia se media nas formas lucro, juros e renda etc. O dinheiro, por exemplo, como mediação da mercadoria, é o modo de existência (ou aparência) da própria mercadoria, não sendo apenas meio da circulação da produção, mas também sua própria mediação, a sua própria determinação (Gunn, 1987).

Gunn (1987) adverte que no processo histórico de expansão capitalista as contradições inerentes à forma da mercadoria (a contradição central é entre valor de uso e valor de troca) não são abolidas, mas fornecem a forma dentro da qual elas têm espaço para se mover e se organizar. A mediação, neste sentido, re-forma as contradições, colocando-as em uma nova aparência.

Um exemplo é, segundo ele, a relação da opressão de classe com a opressão sexual. Embora esta última seja anterior ao capitalismo, a opressão sexual e de classe estão entrelaçadas, o que fica evidente nos modos como o sistema capitalista incorpora elementos relativos à divisão sexual e de gênero, com suas próprias mediações, re-formando este sistema de opressão.

Ao longo de sua longa obra, Marx vai desvelando e descrevendo as "múltiplas determinações" que compõem a mercadoria em um movimento que busca ir do abstrato ao "concreto pensado", de modo a revelar a essência da sociedade capitalista burguesa. Essa essência seria apenas acessível, assim, pelas mediações que totalizam aspectos em um todo internamente relacionado. 
Cumpre lembrar que para Marx, assim como para Hegel, nenhum processo de mediação é definitivo: os termos mediados podem exigir remediação e, longe de ser estático ou meramente "estrutural", o processo de mediação e remediação é aquele em que a práxis da luta de classes está inscrita. A mediação, neste sentido, é, assim como outras, uma categoria destinada a compreensão e também transformação do real cuja "virtude adicional", segundo Gunn (1987), é possibilitar também uma teorização da relação entre a luta de classe e luta de outros tipos, o que atesta o sentido revolucionário da mediação.

\section{Conclusões}

Desde o emprego do termo-médio no silogismo, é possível perceber a gênese da mediação no âmbito das questões que dizem respeito tanto à estruturação da lógica quanto aos problemas da epistemologia.

Desenvolvida a partir da dialética, ela pode ser compreendida como uma categoria eminentemente lógica e ontológica (ou ontocriativa), estando fundamentalmente relacionada à existência do ser social, ao movimento contraditório do real e do pensamento acerca do real.

Além de categoria ontológica, a mediação é categoria epistemológica e metodológica que demarca a indistinção ontológica entre sujeito e objeto do conhecimento, a impossibilidade do conhecimento imediato e sua necessária formulação a partir dos nexos estabelecidos entre as partes de uma totalidade complexa. Compreende um operador metodológico que propõe a compreensão dos processos à luz das relações sociais historicamente organizadas em totalidades nas quais se contrapõem elementos implicados entre si e expressa a interconexão universal de todas as coisas como condição de sua determinação concreta.

A mediação coloca, assim, a inviabilidade de se conhecer o objeto informacional de modo imediato, mas somente a partir das suas complexas articulações históricas, da implicação da informação com a produção da realidade material-simbólica e dos seres sociais. Para a Ciência da Informação, a compreensão dialética traz a necessidade de perseguir os diversos elos que determinam os modos objetivos e subjetivos da produção, circulação, apropriação e consumo informacional, iluminando, portanto, no capitalismo, a indissociável relação entre esta forma-simbólica e a expansão da forma-mercadoria. 
A exequibilidade da mediação, conforme expõe a filósofa brasileira Maria Ciavatta (2001), deve estar implicada, em primeiro momento, com a própria definição do objeto científico.

Considerando que a questão metodológica da construção do objeto implica em sua questão epistemológica, já que "o método não se separa da construção do objeto, "ao contrário, ele o constitui" (Ciavatta, 2001: 208), a autora, ao pensar a mediação por uma perspectiva dialética, apresenta a reconstrução histórica como possibilidade metodológica profícua aberta pelo campo da mediação. Isto porque ela, metodologicamente, aponta para caminho que "propõe a busca das articulações que explicam os nexos e significados do real e levam à construção de totalidades sociais relativas a determinados objetos de estudo" (Ciavatta, 2001: 210).

A categoria ressalta, assim, a necessidade de se ter em primeiro plano a dimensão histórica do objeto informacional, contemplando sua função mediadora na organização da vida material e simbólica ou, em termos gramscianos, na complexa dialética entre a produção da base e da superestrutura.

Esta compreensão não permite que a mediação seja vista por uma perspectiva "ou culturalista ou economicista" (como na falsa dualidade criada entre estudos culturais e de recepção e a economia política), mas na necessária percepção dialética do vínculo entre sentidos e significados produzidos, disseminados e confrontados a partir das práticas informacionais e a organização dos modos historicamente determinados da produção econômica e reprodução social.

O pensamento da informação pela mediação dialética recoloca, assim, a problemática da informação associada à problemática da hegemonia, discussão que marca não apenas a inserção do termo mediação na Comunicação e na C.I. no âmbito da América Latina, mas a própria discussão engendrada pela "epistemologia social" da C.I., que constrói o objeto informacional pela perspectiva da cultura.

Feito de modo recorrente, o emprego da categoria pode ser visto implicando, muitas vezes, um entendimento relativamente compartilhado sobre a potencialidade contra-hegemônica e emancipatória que as "mediações informacionais, comunicacionais e tecnológicas" poderiam trazer para o pensamento teórico e para a práxis dos movimentos sociais, para a emergência de novos espaços e linguagens políticas, para a maior distribuição de poder no campo social e para o fortalecimento das lutas que culminariam na transformação das sociedades latino-americanas.

Um elemento importante dessas análises é a possibilidade múltipla e aberta da construção de sentidos e significados decorrentes da apropriação social das tecnologias que potencialmente transgredem e desafiem o quadro 
de referências simbólicas das hegemonias, forjando outros modos de produção de identidades, de solidariedade e, especialmente, de ação política.

Esta compreensão reivindicou uma "linguagem que procura dizer a imbricação, na economia, da produção simbólica e da política na cultura, sem permanecer na operação dialética uma vez que mistura saberes e sentires, seduções e resistências que a dialética desconhece" (Martín-Barbero, 1997: 259).

Ao centrarem-se na produção de sentidos e nas possibilidades de re-codificação muitas vezes descolada da dialética base-superestrutura, fruto, também, da emergência e consolidação de uma "epistemologia reticular" que foi ganhando espaço e subsumiu a validade epistemológica da totalidade em detrimento de uma "lógica das redes", os empregos da mediação nos estudos informacionais acabaram por não contemplar aspectos seminais de operacionalização do conceito trazidos pelas categorias dialéticas de historicidade, contradição, fetiche, aparência, forma e conteúdo.

O cenário posto hoje, quando a intensa produção da informação é, ao mesmo tempo, produção de uma aguda desinformação e quando a elaboração e o acesso a diversos conteúdos não permitiram o fortalecimento das democracias e de projetos de justiça na América Latina, mas ao contrário, contribuíram para o seu enfraquecimento, evidencia que a análise histórica das mediações centrada especialmente nos aspectos técnicos-semiológicos pode ter prescindido de uma vigilância mais atenta às contradições que sempre tiveram lugar nas diferentes formas da informação relacionadas à comunicação sob o capitalismo (Bolaño, 2000). Contradições estas, presentes desde os primórdios da circulação mercantil, como demonstra Bolaño (2000), até a conversão sistemática das sociedades em "da informação", ou seja, ajustadas à consolidação do capitalismo financeiro, rentista e neoliberal, que utiliza a produção da contra-hegemonia para a reprodução da ordem hegemônica.

O olhar dialético para as mediações a partir das noções de forma e aparência na apreensão das práticas que envolvem os dispositivos de informação e comunicação, ressalta, assim, a relevância de se pensar a dimensão fetichista que atravessa a produção e o uso das tecnologias de infotelecomunicação, iluminando o processo social ocultado pela compreensão das técnicas como algo coerentes em si, como decorrentes do progresso científico ou como resposta às necessidades sociais.

Ao buscar pelas "múltiplas determinações" do objeto informacional, o campo das mediações dialéticas contribui para pensar a problemática posta por Davallon (2006) de como os objetos da Ciência da Informação e Comunicação podem escapar à evidência da sua existência imediata (como meios), da sua existência como suportes ou procedimentos técnicos de comunicação, mantendo, ao mesmo tempo, a sua dimensão técnica de objetos concretos, a sua 
singularidade de objetos materiais, mas tornando visível o invisível da sua organização enquanto objetos que decorrem de formas específicas da produção e reprodução social.

Por fim, apreender as diferentes mediações a partir das quais a informação se realiza no capitalismo, compreendido como uma totalidade histórica em movimento, é um importante horizonte colocado pela dialética das mediações, já que a "moderna concepção da informação" (Day, 2001) ou mesmo a configuração da informação como objeto de interesse científico estão eminentemente vinculadas ao desenvolvimento contínuo, não-homogêneo e contraditório deste sistema.

Considerando esta perspectiva, a mediação pode ser vislumbrada não apenas como intervenientes diversos (técnicos, semiológicos, materiais e simbólicos) das dinâmicas da produção, circulação e apropriação da informação, da construção de conhecimento e da produção de sentido, mas também como articulações reais, vinculadas à economia, à política e à cultura, que produzem e ocultam dialeticamente revelando o fulcro da complexa realidade social.

\section{REFERÊNCIAS}

Abbagnano, Nicola. 2007. Dicionário de Filosofia. São Paulo: Martins Fontes.

Almeida, José. Luiz Vieira de. 2002. "A mediação como fundamento da didática".

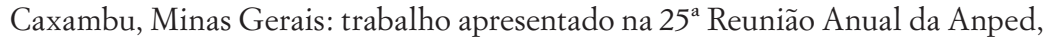
29 de setembro a 2 de outubro.

Araújo, Carlos Alberto Ávila de. 2016. "Novo quadro conceitual para a Ciência da Informação: informação, mediações e cultura”. Tendências da Pesquisa Brasileira em Ciência da Informação, vol. 9, núm. 2: 1-17.

Aristóteles. 2001. Ética a Nicômaco. São Paulo: Martin Claret.

Bolaño, César. 2000. Indústria Cultural, informação e capitalismo. São Paulo: Hucitec.

Bottomore, Thomas. 2010. Dicionário do pensamento marxista. São Paulo: Zahar.

Cabrera, Thiago. 2013. "A mediação histórica e a filosofia do direito em Hegel: entre liberdade e necessidade”. Lex Humana, vol. 4, núm. 2: 157-168.

Ciavatta, Maria. 2001. "O conhecimento histórico e o problema teórico-metodológico das mediações”. Em Gaudêncio Frigotto e Maria Ciavatta, eds., Teoria e educação no labirinto do capital, 2a ed. Petrópolis, R.J.: Voces, 121-144.

Consani, Marciel Aparecido. 2008. "Mediação tecnológica na educação: conceito e aplicações”. São Paulo: Escola de Comunicação e Artes, Universidade de São Paulo, tese de Doutorado em Ciências da Comunicação.

Davallon Jean. 2007. "A mediação: a comunicação em processo?” Prisma.com, núm. 4: 3-36. Disponível em <http://prisma.cetac.up.pt/A_mediacao_a_comunicacao_em_processo.pdf $>$. Acesso em 14 jan. 2018. 
Davallon, Jean. 2006. "Objeto concreto, objeto científico, objeto de investigação". Prisma.com, núm. 2:33-48.

Day, Ronald. 2001. The modern invention of information: Discourse, bistory and power. Carbondale: Southern Illinois University Press.

Dufrêne Bernadette e Michèle Gellereau. 2004. "La médiation culturelle: enjeux professionnels et politiques”. Hermès, núm. 38: 199-206.

Engels, Friedrich. 2008. "Comentários sobre a Contribuição à Crítica da Economia Política de Karl Marx”. Em Karl Marx, Contribuição à Crítica da Economia Política. São Paulo: Expressão Popular, 273-285.

Farias, Marina Giovanna Guedes e Gabriela Belmont Farias. 2017. "Mediação na Ciência da Informação: uma análise bibliométrica na coleção Benancib”, RICI, vol. 10, núm. 2: 332-349. doi: <10.26512/rici.v10.n2.2017.2551>.

Ferrater Mora, José. 1982. Dicionário de Filosofia, 5a ed. Lisboa: Dom Quixote.

Freitas, Lídia. 2001. "Na teia dos sentidos: análise do discurso da Ciência da Informação sobre a atual condição da informação". São Paulo : Escola de Comunicações e Artes, Universidade de São Paulo, tese de Doutorado em Ciências da Comunicação.

Grisales Franco, Lina Maria e Elvia Maria Gonzalez Agudelo. 2010. “De un modo de relacionar dos elementos contrarios a la mediación o Acerca de la aproximación histórica al concepto mediación”. Anagrama, núm. 17: 117-130. Disponível em <http://www.scielo.org.co/pdf/angr/v9n17/v9n17a10.pdf>. Acesso em 05-12-2017.

Guarady, Roger. 1983. Para conhecer o pensamento de Hegel. Porto Alegre: L \& PM.

Gunn, Richard. 1987. "Marxism and mediation". Common Sense, núm. 2 em <https:// marxismocritico.com/2015/07/31/marxism-and-mediation/>. Acesso em 23-03-2018.

Hegel, Georg Wilhelm Friedrich. 2011. Ciência da Lógica- Excertos. São Paulo: Barcarola.

Hegel, Georg Wilhelm Friedrich. 1992. Fenomenologia do Espírito. Parte 1. Petrópolis: Vozes.

Inwood, Michel. 1997. Dicionário Hegel. Río de Janeiro: Zahar.

Japiassú, Hilton e Danilo Marcondes. 2001. Dicionário Básico de Filosofia. Río de Janeiro: Zahar.

Jeanneret, Yves. 2005. "Médiation”. Em Comission Nationale Française, La société de l'information: glossaire critique. 105-107. París: La Documentation Française.

Kofler, Leo. 2010. História e dialética: estudos sobre a metodologia da dialética marxista. Río de Janeiro: UFRJ.

Lalande, Andre. 1993. Vocabulário técnico e crítico da filosofia. São Paulo: Martins Fontes.

Lamizet, Bernard. 1998. La médiation culturelle. París: L'Harmattan.

Legrand, Gerard. 1991. Dicionário de Filosofia. Lisboa: Edições 70.

Marteleto, Regina Maria e Aleixina Maria Lopes Andalécio. 2005. “Jovens e violência: construção de informações nos processos de mediação e apropriação do conhecimento". Marília: trabalho apresentado no $7^{\circ}$ Encontro Nacional de Pesquisa em Ciência da Informação (Enancib), 19 a 22 de novembro. Disponível em $<$ http://www.portalppgci.marilia.unesp.br/enancib/viewabstract.php?id=301>.

Martín-Barbero, Jesús. 1997. Dos meios às mediações: comunicação, cultura e hegemonia. Río de Janeiro: UFRJ.

Martín-Barbero, Jesús e Claudia Barcelos. 2000. "Comunicação e mediações culturais” [Entrevista]. Revista Brasileira de Ciências da Comunicação. São Paulo, vol. 23, núm. 1: 151-163. 
Lage Martins, Ana Amélia. 2010. "Mediação: reflexões no campo da Ciência da Informação”. Minas Gerais: Escola de Ciência da Informação, Universidade Federal de Minas Gerais, dissertação de Mestrado em Ciência da Informação.

Marx, Karl. 2015. "O caráter fetichista da mercadoria e seu segredo". Em As armas da crítica: antologia do pensamento de esquerda, organizado por Ivana Jekings e Emir Sader. 110-121. São Paulo: Boitempo.

Marx, Karl. 2011. Grundrisse. São Paulo: Boitempo.

Marx, Karl. 2008. Contribuição à crítica da economia política. São Paulo: Expressão Popular.

Marx, Karl. 2002. O Capital, livro 1. São Paulo: Boitempo.

O'Connor, Brian. 1999. "The concept of mediation in Hegel and Adorno". Bulletin of Hegel Society of Great Britain, nums. 39/40: 84-96.

Perroti, Edmir e Ivete Pieruccini. 2014. "A mediação cultural como categoria autônoma”. Informação e Informação, vol. 19, núm. 2: 1-22.

Pugliesi, Márcio e Edson Bini. 1997. Pequeno diccionario de filosofia. São Paulo: Hemus.

Rambaldi, Enrico. 1989. "Mediação”, em Dialectica-Enciclopédia Einaudi, organizado por Enrico Rambaldi. Lisboa: Imprensa Nacional-Casa da Moeda, vol. 10: 143-174.

Regimbeau, Gerard. 2011. "Mediation”. Em Approche de l'information-documentation concepts fondateurs. Organizado por Cecile Coubiéres. París: Cépaduès, 76-109.

Silva, Armando Malheiros. 2010. "Mediação e mediadores em Ciência da Informação”. Prisma.com, núm. 9: 1-37. Em <https://repositorio-aberto.up.pt/ bitstream/10216/26174/2/000106387.pdf>. ACesso em 12-08-2018.

Silva, Fernando Santos da, JeffersonVeras Nunes e Lidia Eugenia Cavalcante. 2018. "O conceito de mediação na Ciência da Informação brasileira: uma análise a partir da BRAPCI”. Brazilian Journal Of Information Science, vol. 2, núm. 2: 33-43.

Williams, Raymond. 1985. Keywords: A vocabulary of culture and society. New York: Oxford University Press.

Para citar este texto:

Lage Martins, Ana Amélia. 2019. "Mediação: categoria lógica, ontológica, epistemológica e metodológica”. Investigación Bibliotecológica: archivonomía, bibliotecología e información 33 (80): 133-154. http://dx.doi.org/10.22201/iibi.24488321xe.2019.80.58036 